\title{
Predictors of bankruptcy probability among Malaysian civil servants: examining the subjective measurement
}

\begin{abstract}
Bankruptcy and its impact on the quality of life among Malaysian civil servants has received considerable attention from many authorities. The purpose of this study is to examine the determinant factors of civil servants' bankruptcy probability in Malaysia. The results of this study can be used to predict the possibility of bankruptcy. The knowledge of this early warning model may help to prevent the consequences or reduce the possibility of bankruptcy among Malaysian civil servants. It can be also used for a better understanding of the relationship on bankruptcy probability by highlighting the determinant factors such as asset ownership, attitude towards debt, and financial management practices. Samples were selected by using multi-stage cluster sampling technique among civil servants in public sectors. A total of 399 completed questionnaires were analysed using logistic regression to identify the probability of bankruptcy among the civil servants. The results identified that the possibility of bankruptcy is significantly determined by asset ownership, attitude towards debt, and financial management practices.
\end{abstract}

Keyword: Bankruptcy probability; Asset ownership; Attitude towards debt; Financial management practice 